\title{
Contribution of Organisational Structures to Leaders' and Followers' Performances in Business Enterprises in Papua New Guinea
}

\author{
Pulapa Subba Rao*, Albert C. Mellam, Ponnusamy Manohar \\ School of Business Administration, University of Papua New Guinea, Papua New Guinea
}

Copyright (C) 2015 by authors, all rights reserved. Authors agree that this article remains permanently open access under the terms of the Creative Commons Attribution License 4.0 International License

\begin{abstract}
An appropriate organisational structure that fits into the strategy enables the leaders and followers in enhancing their performances and thereby improving organisational performance. Studies are rare to find in the area of contribution of organisational structure to leaders and followers performance. Therefore, the present study is necessary. Data used for this study were collected from primary and secondary sources. A questionnaire was developed and administered together with interviews conducted. The ' $\mathrm{T}$ ' test (t-value) and co- efficient of correlation ( $\mathrm{r}$ - value) were employed in this study. This paper presents a comparative analysis of impact of organisational structure on leaders and $\mathrm{f}$ followers' performance using three factors viz., bureaucratic structure based, organic structure based and hybrid structure based and performance and satisfaction levels of followers and leaders. Data analysis indicates that the type of organisational structure impacts employee performance in terms of decision-making and implementation; control the process of operations implementation and building relationships and ultimately achievement of organisational goals. The analysis indicates that organic structure results in positive and high employee performance compared to the remaining two types of organisational structures. Therefore, it is suggested that business organisations should consider structuring their organisations around the characteristics of organic structure, unless otherwise the business environment is recessionary.
\end{abstract}

Keywords Bureaucratic Structure, Organic Structure, Hybrid Structure, Leaders, Followers, Performance, and Satisfaction

\section{Introduction}

Organisational structure is an established pattern of relationships among the component parts of an organisational. Structure is made up of three component parts, viz., complexity, formalization and centralisation. Complexity refers to horizontal differentiation, vertical differentiation and locational differentiation. Horizontal differentiation is horizontal separation between units based on jobs and specialisations. Vertical differentiation is based on decision-making and implementation levels. Locational differentiation refers to the degree to which the location of an organisation's offices, plants and employees are geographically spread. Formalisation refers to the degree to which the jobs within the organisational are standardised. High standardisation of jobs results in less freedom and discretion. Centralisation refers to the degree to which decision-making is concentrated at a single point in an organisational [1].

Organisations structured around high degree of complexity, vertical differentiation/ specialisation, centralisation, control are labelled as bureaucratic/ mechanistic structures [2]. These structures heavily rely on policies, procedures, rules and regulations. Organic structures are designed around less horizontal differentiation and specialisation, less formalisation resulting in effective personal co-ordination, loose rules, policies and procedures. These two structures may not respond appropriately to the strategic requirements of various business firms. Hence, hybrid structures are designed with an appropriate mix of characteristics of bureaucratic/ mechanistic structure and organic structures. These hybrid structures may assume the characteristics of bureaucracy in operational core units and organic characteristics in non-core units of the organisational (mechanistic core with organic shell) and organic in operational core and mechanistic in non-core areas (organic core with mechanistic shell) [3].

Efficient strategy implementation largely depends on appropriate fit between organisational structure and the strategy. 


\section{Matching Organisational Structure to Strategy}

The practice of matching organisational structure to the particular needs of strategy is a research based management development. Alfred Chandler, in his research study found that changes in a company's strategy bring about new administrative problems, which in turn, require a new or refashioned structure for the new strategy to be successfully implemented. A company's internal organisational should be reassessed whenever strategy changes [4]. Otherwise, internal problems would crop-up and result in failure in strategy implementation. Structure follows strategy as organisational structure is only a means to an end rather than end itself. Organisational structure is a managerial tool in the process of achievement of organisational objectives. It is easy to coordinate strategic moves across functional areas, if functions, activities and responsibilities are efficiently organised to link strategy and structure.

\section{Need for the Study}

An appropriate organisational structure that fits into the strategy enables the leaders and followers in enhancing their performances and thereby improving organisational performance. Leaders' performance is reflected through making effective decisions, effective control of the decision implementation process and building congenial relations with their followers. The followers' performance is reflected through efficient decision implementation process and building congenial relations with their leaders. Efficient implementation of effective decisions in a congenial relationship environment will result in achievement of organisational goals.

Review of the existing literature on the theme of the study indicates that there are a few studies in other countries [5] [6] [7] [8]. The studies in PNG are rare to find. However, there are a few studies on organizational environment and human resource management in PNG [9] [10] [11][12] [13]. Therefore, the present study is necessary to bridge the gap in the existing literature.

The purpose of this study is to find out the impact of organisational structure on performance of leaders and followers in various business organisations in PNG and to suggest measures to adapt appropriate organisational structures in order to enhance organisational performance in terms of organisational goal achievement.

\section{Methodology and Results}

Data used for this study were collected from primary and secondary sources. A questionnaire was developed and administered together with interviews conducted. This is basically an empirical study about the organisational structures and performance and satisfaction levels of leaders and followers in selected business organisations based on the perception of managers working in business organisations like, ANZ Bank, CPL Limited, Air Lines PNG, Paradise Biscuits Limited Eda Ranu, Telecom PNG Limited, Air Niugini, PNG Power Limited and Post PNG. State Owned Enterprises (SOEs) and Private Enterprises (PEs) were selected to facilitate comparison among bureaucratic, organic and hybrid organisational structures. However, no comparison was made between SOEs and PEs. The organisations were selected purely on judgement basis, as studies of this nature had not been conducted earlier in PNG. Organisations were selected based on the knowledge of a population and the purpose of the study. As such purposive sampling technique was applied. Managers being interviewed fit a specific purpose or description of the study. However, the respondent organisations were grouped into bureaucratic structures, organic structures and hybrid structures based on the characteristics of the organisations.

The questionnaires elicited responses from 132 out of 200 leaders/ managers and 142 out of 200 followers/ subordinates. The quota sampling technique was used because it has the same proportions of individuals as the entire population with respect to known characteristics like qualifications, experiences and gender and the size of the two samples varies in regard to the number of employees.

The ' $\mathrm{T}$ ' test (t-value) and co- efficient of correlation ( $\mathrm{r}$ value) were employed in this study. The ' $\mathrm{T}$ ' test was employed with a view to establishing whether the difference between two sample means is statistically significant or insignificant. The degree of relationship was measured with the help of co- efficient of correlation and other descriptive statistical tools like mean, standard deviation and percentage.

This paper presents a comparative analysis of impact of organisational structure on leaders and followers' performance using three factors viz., bureaucratic structure based, organic structure based and hybrid structure based and performance and satisfaction levels of followers and leaders.

\section{Bureaucratic Structure Based Analysis}

Table-1 reveals the mean score values along with standard deviation (SD) and ' $\mathrm{T}$ ' values of performance of leaders and followers in organisations built on bureaucratic structures on overall as well as factor wise basis according to the hierarchy levels viz., lower level management, middle level management, higher level management and population as a whole, i.e., managers of all levels. The mean values along with ' $\mathrm{T}$ ' values of leaders performance and followers performance on overall basis for the three categories of managers and population as a whole respectively are, $\mathrm{X}_{1}=$ $11.34, \mathrm{X}_{2}=12.14(\mathrm{~T}=0.69) ; \mathrm{X}_{1}=11.80, \mathrm{X}_{2}=12.25(\mathrm{~T}=1.94)$; $\mathrm{X}_{1}=14.75, \mathrm{X}_{2}=13.85(\mathrm{~T}=1.83)$ and $\mathrm{X}_{1}=11.55, \mathrm{X}_{2}=12.32$ $(\mathrm{T}=1.56)$.

Calculated ' $\mathrm{T}$ ' values and mean-scores indicate that the 
performance of leaders and followers at higher level and middle levels are acceptable, but not so at all levels. The expected mean scores index varies between 10 to 15 that indicate the overall performance of the leaders and followers. In the scaling 10 is lower and 15 is higher level. The calculated $t$ value when compared with table values indicates the difference is statistically significant in the lower level of the leaders and followers at the bureaucratic structure.

Table 1. Comparison of Performance of Leaders and Followers on overall as well as factor-wise basis according to Hierarchy (Mean and Standard Deviation along with 't' values) in Organisations based on Bureaucratic structure

\begin{tabular}{|c|c|c|c|c|c|}
\hline Variables & \multicolumn{5}{|c|}{ Lower level of management } \\
\hline & \multicolumn{2}{|c|}{$\mathbf{X}_{\mathbf{1}}$} & \multicolumn{2}{c|}{$\mathbf{X}_{\mathbf{2}}$} & ' $\mathbf{'}$ \\
\hline & Mean & SD & Mean & SD & Value \\
\hline Decision & 10.87 & 4.56 & 11.63 & 2.63 & 0.85 \\
\hline Control & 10.73 & 5.11 & 11.84 & 3.45 & 1.83 \\
\hline Relationship & 10.77 & 4.55 & 11.55 & 3.59 & 0.57 \\
\hline Goal achievement & 12.80 & 4.85 & 13.72 & 4.25 & 1.58 \\
\hline Overall & 11.34 & 4.85 & 12.14 & 3.65 & 0.69 \\
\hline
\end{tabular}

\begin{tabular}{|c|c|c|c|c|c|}
\hline Variables & \multicolumn{5}{|c|}{ Middle level of management } \\
\hline & \multicolumn{2}{|c|}{$\mathbf{X}_{\mathbf{1}}$} & \multicolumn{2}{c|}{$\mathbf{X}_{\mathbf{2}}$} & 't' \\
\hline & Mean & SD & Mean & SD & Value \\
\hline Decision & 11.41 & 4.51 & 12.75 & 3.66 & 1.68 \\
\hline Control & 11.91 & 3.25 & 11.00 & 4.55 & 1.96 \\
\hline Relationship & 10.78 & 3.62 & 12.32 & 4.12 & 1.87 \\
\hline Goal achievement & 13.58 & 3.49 & 13.13 & 5.79 & 1.42 \\
\hline Overall & $\mathbf{1 1 . 8 0}$ & $\mathbf{2 . 7 7}$ & $\mathbf{1 2 . 2 5}$ & $\mathbf{4 . 6 0}$ & $\mathbf{1 . 9 4}$ \\
\hline
\end{tabular}

\begin{tabular}{|c|c|c|c|c|c|}
\hline Variables & \multicolumn{5}{|c|}{ Higher level of management } \\
\hline & \multicolumn{2}{|c|}{$\mathbf{X}_{\mathbf{1}}$} & \multicolumn{2}{c|}{$\mathbf{X}_{\mathbf{2}}$} & ' $\mathbf{'}$ \\
\hline & Mean & SD & Mean & SD & Value \\
\hline Decision & 13.81 & 3.57 & 13.20 & 2.72 & 1.65 \\
\hline Control & 14.26 & 2.67 & 13.00 & 3.28 & 2.20 \\
\hline Relationship & 13.65 & 3.53 & 13.20 & 2.72 & 1.42 \\
\hline Goal achievement & 17.09 & 2.44 & 15.00 & 3.44 & 1.43 \\
\hline Overall & 14.75 & 3.12 & 13.85 & 3.41 & 1.83 \\
\hline
\end{tabular}

\begin{tabular}{|c|c|c|c|c|c|}
\hline Variables & \multicolumn{5}{|c|}{ Population as a whole } \\
\hline LOH & \multicolumn{2}{|c|}{$\mathbf{X}_{\mathbf{1}}$} & \multicolumn{2}{|c|}{$\mathbf{X}_{\mathbf{2}}$} & ' $\mathbf{'}$ \\
\hline & Mean & SD & Mean & SD & Value \\
\hline Decision & 11.25 & 4.60 & 12.27 & 3.15 & 2.63 \\
\hline Control & 11.31 & 4.63 & 11.72 & 3.91 & 1.00 \\
\hline Relationship & 10.81 & 4.38 & 11.88 & 3.81 & 2.47 \\
\hline Goal achievement & 13.21 & 4.55 & 13.86 & 4.86 & 1.44 \\
\hline Overall & 11.55 & 4.55 & 12.32 & 3.96 & 1.56 \\
\hline
\end{tabular}

* $\mathrm{X}_{1}=$ Mean score of Leaders, $* \mathrm{X}_{2}=$ Mean score of Followers

\section{Organic Structure Based Analysis}

Table 2. Comparison of Performance of Leaders and Followers on overall as well as factor-wise basis according to Hierarchy (Mean and Standard Deviation along with ' $t$ ' values) in Organisations based on Organic structure

\begin{tabular}{|c|c|c|c|c|c|}
\hline Variables & \multicolumn{5}{|c|}{ Lower level of management } \\
\hline & \multicolumn{2}{|c|}{$\mathbf{X}_{1}$} & \multicolumn{2}{c|}{$\mathbf{X}_{\mathbf{2}}$} & 't' \\
\hline & Mean & SD & Mean & SD & Value \\
\hline Decision & 10.27 & 3.96 & 12.5 & 1.71 & 4.84 \\
\hline Control & 10.66 & 4.16 & 11.92 & 3.06 & 1.86 \\
\hline Relationship & 10.77 & 3.82 & 11.05 & 3.87 & 1.26 \\
\hline Goal achievement & 11.32 & 3.67 & 15.01 & 2.96 & 3.92 \\
\hline Overall & 11.01 & 3.17 & 12.86 & 2.45 & 2.37 \\
\hline
\end{tabular}

\begin{tabular}{|c|c|c|c|c|c|}
\hline Variables & \multicolumn{5}{|c|}{ Middle level of management } \\
\hline & \multicolumn{2}{|c|}{$\mathbf{X}_{\mathbf{1}}$} & \multicolumn{2}{c|}{$\mathbf{X}_{\mathbf{2}}$} & 't' \\
\hline & Mean & SD & Mean & SD & Value \\
\hline Decision & 12.35 & 3.97 & 11.79 & 3.07 & 1.79 \\
\hline Control & 12.08 & 4.24 & 13.04 & 3.47 & 1.98 \\
\hline Relationship & 11.71 & 3.72 & 12.37 & 2.21 & 2.18 \\
\hline Goal achievement & 14.18 & 3.07 & 14.00 & 2.77 & 1.27 \\
\hline Overall & 12.58 & 3.01 & 12.8 & 2.39 & 1.98 \\
\hline
\end{tabular}

\begin{tabular}{|c|c|c|c|c|c|}
\hline Variables & \multicolumn{5}{|c|}{ Higher level of management } \\
\hline & \multicolumn{2}{|c|}{$\mathbf{X}_{\mathbf{1}}$} & \multicolumn{2}{c|}{$\mathbf{X}_{\mathbf{2}}$} & ' $\mathbf{t}$ \\
\hline & Mean & SD & Mean & SD & Value \\
\hline Decision & 11.79 & 3.84 & 13.01 & 3.61 & 2.0 \\
\hline Control & 12.27 & 3.87 & 10.78 & 4.45 & 1.94 \\
\hline Relationship & 11.41 & 3.13 & 11.92 & 3.17 & 1.68 \\
\hline Goal achievement & 14.11 & 2.93 & 13.71 & 3.69 & 1.49 \\
\hline Overall & 11.60 & 3.94 & 11.65 & 3.05 & 1.67 \\
\hline
\end{tabular}

\begin{tabular}{|c|c|c|c|c|c|}
\hline \multirow[t]{3}{*}{ Variables } & \multicolumn{5}{|c|}{ Population as a whole } \\
\hline & \multicolumn{2}{|c|}{$\mathrm{x}_{1}$} & \multicolumn{2}{|c|}{$\mathbf{X}_{2}$} & ' $t$ ' \\
\hline & Mean & SD & Mean & SD & Value \\
\hline Decision & 11.57 & 4.05 & 12.47 & 3.31 & 2.5 \\
\hline Control & 11.73 & 4.18 & 11.83 & 4.03 & 1.22 \\
\hline Relationship & 11.35 & 2.91 & 11.87 & 3.84 & 1.24 \\
\hline Goal achievement & 13.62 & 3.33 & 14.09 & 3.37 & 0.94 \\
\hline Overall & 12.07 & 3.11 & 12.57 & 2.7 & 1.62 \\
\hline
\end{tabular}

* $\mathrm{X}_{1}=$ Mean score of SOEs, * $\mathrm{X}_{2}=$ Mean score of PEs

Table-2 reveals the mean score values along with standard deviation (SD) and ' $\mathrm{T}$ ' values of performance of leaders and followers in organisations built on organic structures on overall as well as factor wise basis according to the hierarchy levels viz., lower level management, middle level management, higher level management and population as a whole, i.e., managers of all levels. The mean values along with ' $\mathrm{T}$ ' values of leaders performance and followers 
performance on overall basis for the three categories of managers and population as a whole respectively are, $\mathrm{X}_{1}=$ $11.01, \mathrm{X}_{2}=12.86(\mathrm{~T}=2.37) ; \mathrm{X}_{\mathrm{I}}=12.58, \mathrm{X}_{2}=12.80(\mathrm{~T}=1.98)$; $\mathrm{X}_{\mathrm{I}}=11.60, \mathrm{X}_{2}=11.65(\mathrm{~T}=1.67)$ and $\mathrm{X}_{\mathrm{I}}=12.07, \mathrm{X}_{2}=12.57$ $(\mathrm{T}=1.62)$. This reveals that performance of leaders and followers is high at lower level, middle and higher levels of management relating to decision, and goal achievement. But performances of leaders and followers do not differ significantly at lower level management with regard to all criteria of performance. However, the performance with regard to relationship is high at higher and middle level and moderate at lower level management. Performance relating to control at middle and higher levels is high and moderate at lower level.

Calculated ' $\mathrm{T}$ ' values and mean-scores indicate that the performance of leaders and followers at lower level and middle levels are acceptable, but not so at all levels. The expected mean scores index varies between 10 to 15 that indicate the overall performance of the leaders and followers. In the scaling 10 is lower and 15 is higher level. The calculated $t$ value when compared with table values indicates the difference is statistically significant in the higher level of the leaders and followers at the organic structure.

\section{Hybrid structure Based Analysis}

Table-3 reveals the mean score values along with standard deviation (SD) and ' $\mathrm{T}$ ' values of performance of leaders and followers in organisations built on hybrid structure on overall as well as factor wise basis according to the hierarchy levels viz., lower level management, middle level management, higher level management and population as a whole, i.e., managers of all levels. The mean values along with ' $\mathrm{T}$ ' values of leaders performance and followers performance on overall basis for the three categories of managers and population as a whole respectively are, $\mathrm{X}_{\mathrm{I}}=$ $11.55, \mathrm{X}_{2}=11.29(\mathrm{~T}-1.43) ; \mathrm{X}_{\mathrm{I}}=12.57, \mathrm{X}_{2}=12.29(\mathrm{~T}-2.21)$; $\mathrm{X}_{\mathrm{I}}=11.55, \mathrm{X}_{2}=12.40(\mathrm{~T}-2.29)$ and $\mathrm{X}_{\mathrm{I}}=11.16, \mathrm{X}_{2}=11.38$ (T-1.39). This reveals that performance of leaders and followers is moderately high at higher levels of management relating to decision, and goal achievement, but low in control and relationship aspects. But, the performance at middle level and low levels of management is low at lower and middle levels of management. However, performance with regard to control bears mixed results in hybrid structures as it is moderate at higher level and high at middle level and lower levels of management in hybrid structures. Performance relating to relationship is moderate at middle and lower levels and high at higher level of management in hybrid structures.

Calculated ' $\mathrm{T}$ ' values and mean-scores indicate that the performance of leaders and followers at higher level, middle levels lower level are acceptable. The expected mean scores index varies between 10 to 15 which indicate the overall performance of the leaders and followers. In the scaling 10 is lower and 15 is higher level. The calculated $t$ value when compared with table values indicates the difference is not statistically significant in the all level of the leaders and followers at the organic structure.

Table 3. Comparison of Performance of Leaders and Followers on overall as well as factor-wise basis according to Hierarchy (Mean and Standard Deviation along with 't' values) in Organisations based on Hybrid structure

\begin{tabular}{|c|c|c|c|c|c|}
\hline Variables & \multicolumn{5}{|c|}{ Lower level of management } \\
\hline & \multicolumn{2}{|c|}{$\mathbf{X}_{\mathbf{1}}$} & \multicolumn{2}{c|}{$\mathbf{X}_{\mathbf{2}}$} & ' $\mathbf{'}^{\prime}$ \\
\hline & Mean & SD & Mean & SD & Value \\
\hline Decision & 10.92 & 3.0 & 10.82 & 2.09 & 2.52 \\
\hline Control & 10.61 & 3.19 & 9.76 & 2.53 & 2.65 \\
\hline Relationship & 10.78 & 2.63 & 10.06 & 2.78 & 2.38 \\
\hline Goal achievement & 12.68 & 3.22 & 10.71 & 3.83 & 1.98 \\
\hline Overall & 11.55 & 3.02 & 11.29 & 2.88 & 1.43 \\
\hline
\end{tabular}

\begin{tabular}{|c|c|c|c|c|c|}
\hline Variables & \multicolumn{5}{|c|}{ Middle level of management } \\
\hline & \multicolumn{2}{|c|}{$\mathbf{X}_{\mathbf{1}}$} & \multicolumn{2}{c|}{$\mathbf{X}_{\mathbf{2}}$} & 't' \\
\hline & Mean & SD & Mean & SD & Value \\
\hline Decision & 11.92 & 3.06 & 11.92 & 2.69 & 1.98 \\
\hline Control & 11.50 & 2.84 & 11.92 & 2.69 & 2.76 \\
\hline Relationship & 11.95 & 2.64 & 11.85 & 3.52 & 2.10 \\
\hline Goal achievement & 12.34 & 3.23 & 12.85 & 3.47 & 2.44 \\
\hline Overall & 12.57 & 2.95 & 12.29 & 3.18 & 2.21 \\
\hline
\end{tabular}

\begin{tabular}{|c|c|c|c|c|c|}
\hline Variables & \multicolumn{5}{|c|}{ Higher level of management } \\
\hline & \multicolumn{2}{|c|}{$\mathbf{X}_{\mathbf{1}}$} & \multicolumn{2}{|c|}{$\mathbf{X}_{\mathbf{2}}$} & ' $\mathbf{'}$ \\
\hline & Mean & SD & Mean & SD & Value \\
\hline Decision & 12.23 & 3.82 & 12.52 & 3.27 & 1.35 \\
\hline Control & 12.21 & 2.68 & 12.18 & 3.88 & 2.36 \\
\hline Relationship & 11.61 & 2.97 & 11.56 & 2.27 & 1.57 \\
\hline Goal achievement & 12.95 & 3.07 & 15.00 & 4.42 & 2.75 \\
\hline Overall & 11.55 & 2.88 & 12.40 & 2.75 & 2.29 \\
\hline
\end{tabular}

\begin{tabular}{|c|c|c|c|c|c|}
\hline Variables & \multicolumn{5}{|c|}{ Population as a whole } \\
\hline & \multicolumn{2}{|c|}{$\mathbf{X}_{\mathbf{1}}$} & \multicolumn{2}{|c|}{$\mathbf{X}_{\mathbf{2}}$} & ' $\mathbf{t}$ ' \\
\hline LOE & Mean & SD & Mean & SD & Value \\
\hline Decision & 11.7 & 3.01 & 12.11 & 2.41 & 1.14 \\
\hline Control & 12.15 & 2.29 & 11.76 & 3.16 & 1.91 \\
\hline Relationship & 11.48 & 2.69 & 11.87 & 2.71 & 1.95 \\
\hline Goal achievement & 13.71 & 3.26 & 12.16 & 3.45 & 1.78 \\
\hline Overall & 11.16 & 2.99 & 11.38 & 2.85 & 1.39 \\
\hline
\end{tabular}

$\mathrm{X}_{1}=$ Mean score of SOEs, * $\mathrm{X}_{2}=$ Mean score of PEs

\section{Correlation between Organisational Structures and Performance \& Satisfaction}

An attempt was made to find out the correlation between 
organisational structure and performance and satisfaction of leaders and followers viz., leaders' performance, followers' performance, leaders' satisfaction and followers' satisfaction. Leader and follower satisfaction related data were collected and both were used to analyse the association impact of these two variables. The coefficient of correlation ( $\mathrm{r}-$ value) has been calculated to identify the degree of correlation between organisational structure and performance and satisfaction of leaders and followers. The ' $\mathrm{T}$ ' test has been used to verify whether organisational structure and performance and satisfaction of leaders and followers are significantly correlated in the population or not.

Table-4 presents correlation matrix of bureaucratic structures with performance and satisfaction of leaders and followers.

Table 4. Correlation Matrix along with ' $\mathrm{T}$ ' values (in brackets) for Performance and Satisfaction in Bureaucratic Structures

\begin{tabular}{|c|c|c|c|c|c|}
\hline \multicolumn{2}{|c|}{ Variables } & VI & V2 & V3 & V4 \\
\hline V1 & Leader Performance & -- & $\begin{array}{c}0.54^{*} \\
(1.25)\end{array}$ & $\begin{array}{c}0.65 \\
(1.77)\end{array}$ & $\begin{array}{c}0.37^{*} \\
(0.87)\end{array}$ \\
\hline V2 & Follower Performance & -- & -- & $\begin{array}{c}0.21 \\
(0.04)\end{array}$ & $\begin{array}{c}0.28 \\
(0.65)\end{array}$ \\
\hline V3 & Leader Satisfaction & -- & -- & -- & $\begin{array}{c}0.57^{*} \\
(1.05)\end{array}$ \\
\hline V4 & Follower Satisfaction & -- & -- & -- & -- \\
\hline
\end{tabular}

Note: * Significant at $5 \%$ level, $\boldsymbol{V}$ - Variables

It is observed from Table-4 that the correlations among leaders and follower performance and satisfaction in bureaucratic structure are positive, but insignificant. Similarly, the correlations among the followers and leader performance and satisfaction are also positive in bureaucratic structures, but insignificant as per ' $\mathrm{T}$ ' values. It indicates that the practice of bureaucratic structure did not result in significant outcome. In other words, it indicates that bureaucratic organisational structure did not result in significant performance and satisfaction by leaders and followers.

Table-5 depicts correlation matrix with ' $\mathrm{T}$ ' values of organic structures with performance and satisfaction of leaders and followers.

Table 5. Correlation Matrix along with ' $\mathrm{T}$ ' values (in brackets) for Performance and Satisfaction in Organic Structures

\begin{tabular}{|c|c|c|c|c|c|}
\hline \multicolumn{2}{|c|}{ Variables } & VI & V2 & V3 & V4 \\
\hline VI & Leader Performance & -- & $\begin{array}{c}0.85 \\
(0.72)\end{array}$ & $\begin{array}{c}0.78 \\
(1.24)\end{array}$ & $\begin{array}{c}0.75 \\
(0.77)\end{array}$ \\
\hline V2 & Follower Performance & -- & -- & $\begin{array}{c}0.79 \\
(1.93)\end{array}$ & $\begin{array}{c}0.75^{*} \\
(3.32)\end{array}$ \\
\hline V3 & Leader Satisfaction & -- & -- & -- & $\begin{array}{c}0.76^{*} \\
(2.03)\end{array}$ \\
\hline V4 & Follower Satisfaction & -- & -- & -- & -- \\
\hline
\end{tabular}

Note: * Significant at $5 \%$ level, $\boldsymbol{V}$-Variables

It is observed from Table-5 that the correlations among the leaders and followers performance and satisfaction in organic structure are positive and moderate. Similarly, correlation among the performance and satisfaction of leaders and followers are also positive and high. It indicates that organic structure resulted in positive and high performance and satisfaction of followers and leaders.

Table-6 depicts correlation matrix with ' $\mathrm{T}$ ' values of hybrid structures with performance and satisfaction of leaders and followers.

Table 6. Correlation Matrix along with ' $T$ ' values (in brackets) for Performance and Satisfaction in Hybrid Structure

\begin{tabular}{|c|c|c|c|c|c|}
\hline \multicolumn{2}{|c|}{ Variables } & VI & V2 & V3 & V4 \\
\hline VI & Leader Performance & -- & $\begin{array}{c}0.65 \\
(1.92)\end{array}$ & $\begin{array}{c}0.68 \\
(1.64)\end{array}$ & $\begin{array}{c}0.65 \\
(.77)\end{array}$ \\
\hline V2 & Follower Performance & -- & -- & $\begin{array}{c}0.69 \\
(1.73)\end{array}$ & $\begin{array}{c}0.68^{*} \\
(2.32)\end{array}$ \\
\hline V3 & Leader Satisfaction & -- & -- & -- & $\begin{array}{c}0.66^{*} \\
(2.03)\end{array}$ \\
\hline V4 & Follower Satisfaction & -- & -- & -- & -- \\
\hline
\end{tabular}

Note: * Significant at $5 \%$ level, $\mathrm{V}-$ Variables

It is observed from Table- 6 that the correlations among the leaders and followers' performance and satisfaction in hybrid structure positive and high. Similarly, correlation among the performance and satisfaction of leaders and followers are also positive and high. It indicates that the hybrid structure resulted in positive and high performance and satisfaction of followers and leaders.

\section{Conclusions and Further Research}

On the basis of above analysis and results, it is inferred that the Type of the organisational structure impacts employee performance in terms of decision-making and implementation, control the process of operations implementation and building relationships and ultimately achievement of organisational goals. The data analysis reveals that performance relating to decision-making and implementation and achievement of organisational goals in bureaucratic structures is low at all levels of management whereas it is moderate at higher level of management in hybrid structures and high in organic structures.

Employee performance relating to control is high in bureaucratic structures and low at middle and higher levels of management in organic structures. However, performance with regard to control bears mixed results in hybrid structure as it is moderate at higher level and high at middle level and lower levels of management in hybrid structures.

Employee performance relating to building congenial relationships is moderate at middle and low at lower and high level of bureaucratic structure. It is positive at middle level and higher levels of management and moderate at lower level of management in organic structure. Performance relating to relationship is moderate at middle and lower levels and high at higher level of management in hybrid structures

An analysis of correlation between organisational structure and performance and satisfaction of leaders and followers' viz., leaders' performance, followers' 
performance, leaders' satisfaction and followers' satisfaction indicates that bureaucratic organisational structure did not result in significant performance and satisfaction by leaders and followers, whilst organic structure resulted in positive and high performance and satisfaction of followers and leaders. The hybrid structure resulted in positive and moderate performance and satisfaction of followers and leaders.

The analysis indicates that organic structure results in positive and high employee performance compared to the remaining two types of organisational structures. Therefore, it is suggested that business organisations should consider structuring their organisations around the characteristics of organic structure, unless otherwise the business environment is recessionary.

This paper presented some early findings relating to considering organic structure, while designing an organisational structure by business organisations. In-depth investigation is necessary covering various other issues uncovered in this study and expanding the coverage of the organisations in various countries, strategies, environmental factors and the like for validating the conclusions of this study and making firm recommendations.

\section{Acronyms Used}

$\mathrm{PNG}=$ Papua New Guinea, $\mathrm{SOE}=$ State Owned Enterprises, $\mathrm{PE}=$ Private Enterprises.

\section{REFERENCES}

[1] Henry Mintzberg, Structure in Fives: Designing Effective Organizations, Englewood Cliffs. New Jersey, Prentice-Hall, 1983.

[2] Max Weber, The Theory of Social and Economic Organization, Translated by A.M. Henderson and H.T.
Parsons. New York: The Free Press, 1947.

[3] Jackwood, et.al., Organizational Behaviour, New York, John Wiley,2001.

[4] Alfred D. Chandler, "Strategy and Structure," in the "History of American Enterprise," .Cambridge, M.I.T. Press, 1962.

[5] Datta K.V., "Leadership and Motivation in Banking Industry in India" Personnel Today, vol. XX, no.3,1999.

[6] Datta K.V., "Leadership and Motivation in Banking Industry in India" Indian Journal of Labour Economics, vol. XXXXII, no.1,2004.

[7] Prasad, MS., "Leadership and Personality Development in Ship Building Industry in India", Indian Journal of Commerce, vol. 47 , no. 2,2001 .

[8] Mukherjee R, "Impact of Leadership on Performance", Labour Chronicle, vol.26, no.5, 2004.

[9] Kavanamur, D., Okole, H with Manning, M. and Levantis, T., "Understanding reforms in Papua New Guinea: an analytical evaluation", A Global Development Network and AusAID study, Monograph,2004.

[10] Imbun B.Y. and Richard Morres, "Labour and Mining in Remote Areas" in Imbun,B.Y., and McGavin P. A., (eds.) Mining in Papua New Guinea, University of Papua New Guinea Press, Port Moresby, 81-95,2001.

[11] Imbun, B. Y., "Human Resource Management in PNG Mining: Evidences from Porgera", in Imbun, B. Y. and McGavin, P. A., (eds) Mining in Papua New Guinea, University of Papua New Guinea Press, Port Moresby, 96-112, 2001.

[12] Subba Rao, Pulapa, Manohar,P., \& Mellam A.C., "Leadership Styles and their Contribution to Performance and Satisfaction of Leaders and Followers in State Owned and Private Enterprises in Papua New Guinea", Delhi Business Review, vol.9, no.1, 2008.

[13] McGavin P. A., Jones L. T., and Imbun B.Y., "In Country fly-in/fly-out and national HR Development: Evidence from PNG", in Imbun, B. Y. and McGavin P. A., (eds.) Mining in Papua New Guinea, University of Papua New Guinea Press, Port Moresby, 113-131, 2001. 